\title{
Studying reading during writing: new perspectives in research
}

\author{
Åsa Wengelin · Mariëlle Leijten · Luuk Van Waes
}

Published online: 23 May 2009

(C) Springer Science+Business Media B.V. 2009

The most worn-out cliché within writing research is probably that writing is a complex process. Nevertheless it is true. The generation of a coherent text involves a large and complex set of cognitive processes requiring referential, pragmatic, linguistic, and graphomotor knowledge (Alamargot, Chanquoy, \& Rijlaarsdam, 2001). This special issue focuses on one specific sub-process, the process of reading during writing.

Like models of spoken language (e.g., Levelt, 1989), most models of writing include components of message construction, formulating, transcription (articulation in speaking), and monitoring. Moreover, most writing models include a module of reviewing/revision. For an overview, see Alamargot, Chanquoy, and Rijlaarsdam (2001). Most likely, the most cited model of writing is that of Hayes and Flower's (1980). In this model, the three main components were planning, translating, and reviewing.

The cognitive demands of a given component are highly dependent on how automatized the component is. It is generally assumed that lower-level processes such as lexical access (McCutchen \& Crain-Thoreson, 1994), typing (Alvès, Castro, de Sousa, \& Strömqvist, 2007), and shaping of letters in handwriting (Berninger, Cartwright, Yates, Swanson, \& Abbott, 1994; Longcamp et al., 2008), which all would take place during Hayes and Flower's (1980) translation phase, can be automatized with practice. Higher-level conceptual processes on the other hand,

\footnotetext{
A. Wengelin

University of Lund, Lund, Sweden

M. Leijten · L. Van Waes $(\bowtie)$

University of Antwerp, Prinsstraat 13, 2000 Antwerp, Belgium

e-mail: luuk.vanwaes@ua.ac.be

URL: http://www.ua.ac.be/luuk.vanwaes

M. Leijten

Staffordshire University, Stafford, UK
} 
such as planning and revising, involve decisions about content selection and organization. Hence, they require constant attentional control, are very difficult to automatize, and are therefore considered more demanding for most writers (Kellogg, 1996, 2008).

According to Hayes and Flower (1980), the different sub-processes are rarely performed as discrete, deliberate steps, but typically occur as multiple, iterative cycles. However, despite about 30 years of research, our understanding of the different sub-processes of writing and the dynamics of how they interact still remains quite limited. The challenge of developing an adequate cognitive theory of text production is to describe how the various inputs into the writing system are processed in order to output a coherent text (Wengelin et al., 2009).

\section{Reading the text produced so far}

In a revised model of the original Hayes and Flower (1980) model, Hayes (1996) proposed that the primary cognitive functions involved in writing are text interpretation, reflection, and text production. These processes interact with each other as well as with individual factors, such as motivation, long-term memory, and short-term memory on the one hand, and with the social and physical environment on the other. One of the most interesting differences between the 1980 model and the 1996 model is the shift from revision as a basic process to text interpretation (reading). According to Hayes, text interpretation is a function that creates internal representations from linguistic and graphic inputs. He suggested three types of reading activities during writing: (a) reading source texts; (b) reading to define tasks; and (c) reading to evaluate. The input for the latter is the part of the physical environment that Hayes (1996) called "the text produced so far", i.e., the emerging text.

One of the main functions of reading for evaluation would be to serve as a basis for revision. Hayes (1996) argued that text-interpretation activities involved in writing overlap with those involved in normal reading activities, such as the reading of novels (i.e., reading for comprehension), but that reading for revision also includes other activities. In both reading for revision and reading for comprehension, we are concerned with the text's message. However, in reading for revision we are also concerned with the identification of various text characteristics, such as spelling errors, poor lexical choice, or poor organization (Hayes, 1996). Furthermore, reading for evaluation could also involve considerations on whether the text conforms to the structures of the given genre, and achieves the writers' communicative and rhetorical goals as well as looking for "opportunities for improvements that do not stem from problems" (Hayes, 1996, p. 15). In other words, writers may also engage in reading to facilitate other parts of the writing process than revision. Already, in 1979, Pianko proposed that writers looked back to what they had written earlier in order to decide what to write next. This agrees with the proposal of Holmqvist, Holsanova, Johansson, and Strömqvist (2004), that writers may look back at their text to remind themselves of what they have already covered, to refresh their memory of the syntactic frame currently being used, or to find prompts enabling them to search for and retrieve more ideas. Moreover, 
Wengelin et al., (2009) suggested that on top of reading for evaluation, writers might look at their emerging text to prompt content generation, to manage reference and so maintain cohesion, and to engage in metacognitive strategies for revision.

\section{“Reading" dynamic text}

Constant access to the emerging text distinguishes written language production from spoken language production, in that the language just produced remains visible, accessible, and hence revisable during the entire production process. Thus, the emerging text could function as a visual external storage, which could be used to decrease the cognitive load of the writer, and it is generally assumed that good writers use this more than poor writers. This idea was supported by a study by Breetvelt, Van den Bergh, and Rijlaarsdam (1996) who found that rereading was positively correlated with text quality. However, neither of the studies that approached this topic in the present special issue found a simple correlation between text characteristics and quantity of reading.

Despite the case that most models of writing (for an overview, see Alamargot, Chanquoy, \& Rijlaarsdam, 2001) include a component of reading/reviewing, we have little empirical knowledge about how the visual trace of the emerging text is used by the writer. However, it would probably be uncontroversial to claim that most (sighted) writers typically spend a certain proportion of time looking back over the text that they have written. It is for example an open question to what extent Hayes's assumption that the process of reading during writing overlaps with reading of static texts, such as novels or journals, and thus to what extent definitions of reading used in traditional reading research can be used in writing research. According to the extensive literature on eye movements in reading (e.g., Liversedge \& Findlay, 2000; Rayner, 1998; Starr \& Rayner, 2001), reading tends to proceed through a sequence of rapid saccades, when the eye moves between and within words, and fixations, when the gaze remains relatively fixed within a single word. Reading is often identified as three or more consecutive fixations in the same direction with a maximum time between the end point of one fixation and the start point of the succeeding fixation. In an attempt to use this definition of reading, Johansson, Johansson, Wengelin, and Holmqvist (2008) found that most writers read less than $20 \%$ of the time they look at the screen during the writing sessionirrespective of whether they are skilled typists who look at the screen most of the time or less skilled typists who need to look at the keyboard during most of the writing session. Consequently, the research question should most likely be extended from reading during writing to how writers use visual feedback from their emerging texts during the text production process, i.e., what they look at, when, why, in what contexts, at what stages of the writing process, and finally, to what extent these processes could be related to "normal reading processes".

The limited knowledge we have of reading during writing contrasts with the relatively detailed understanding that we have of the cognitive processes associated with text comprehension (e.g., Crain-Thoreson, Lippman, \& McClendon-Magnuson, 1997; Just \& Carpenter, 1980, 2002; Kintsch \& Rawson, 2005). Wengelin et al. 
(2009) argued that one of the reasons for this is that while reading researchers study a cognitive process directed toward a static stimuli, writing researchers interested in reading during writing study a cognitive process directed towards a target that constantly changes - as part of a complex production process of which reading is just a small part. This makes it difficult for writing researchers to give the participants well-defined limited tasks with easily measured outcomes, similar to those used in reading research. With the exception of, some studies on proofreading of familiar text (e.g., Bisaillon, 2007; Hacker, Plumb, Butterfield, Quathamer, \& Heineken, 1994; Levy, 1983; Pilotti, Chodorow, \& Maxwell, 2006), or errordetection and correction during writing (Leijten, 2007), little earlier empirical research has been published on reading during writing. One exception is the study by Breetvelt et al., (1996) mentioned above.

Another reason for our limited knowledge of how writers use visual feedback during writing has probably been the lack of available and affordable tools. Whereas think-aloud protocols, for instance, are sufficient for reporting the engagement of a given process, they do not suffice when it comes to explaining how that process operates (Alamargot, Plane, Lambert, \& Chesnet, 2009). A few studies with focus on text copying have explored typists' eye movements within the text that they are copying (Butsch, 1932; Inhoff \& Gordon, 1998), but since these studies in fact studied "reading" of static texts, they did not contribute towards the study of the reading behaviour of dynamic texts. Recently, systems were developed to facilitate recording eye movements during typing-keystroke logging combined with eye tracking (Andersson et al., 2006; Simpson \& Torrance, 2007; Wengelin et al., 2009) and handwriting - combined analysis of graphomotor activities and eye movements (Alamargot, Chesnet, Dansac, \& Ros, 2006; Chesnet \& Alamargot, 2006). Thanks to these new technical developments we are now able to collect detailed temporal data on the writing process as well as the eye movements: What does a writer look at any given moment? For how long? At what stage of the writing process? And finally, how does the visual behaviour relate to other parts of the writing process and in what ways does it affect the characteristics of the final text?

By putting together this special issue, we hope to be able to convince the readers that information of when and where writers fixate their emerging texts has the potential to inform theories about the complex cognitive processes that underlie written production and the related cognitive costs. The included papers focus on different aspects of the writing process, as well as on different linguistic levels of the text, but all of them have in common that they investigate eye movements in combination with different ways of inputting text. Through these papers, we aim at contributing a little towards answering the question on how writers use visual feedback from their emerging texts during the text production process. In the section below, an overview of the papers included in the special issue is given.

\section{Overview of the special issue}

This special issue contains five articles. While each paper takes up a different perspective on the central theme, the research presented is closely related. In the 
first paper Beers, Quinlan, and Harbaugh report on a study, in which they employed eye-tracking technology for studying ongoing reading processes. In their study young, unskilled students are engaged in writing a text: an expository essay or a narrative. Their method consisted of monitoring the participants' eye movements while they complete their text. According to the authors, the presence of a typist takes away the burden of actually having to enter the text themselves, and assures less focus on mechanical aspects and other low level writing activities (e.g., spelling). The eye-movement data were analyzed in relation to four areas of interest: reading at the point of inscription, local reading, global reading, and prompt reading. Results indicated a significant relationship between participants' rate of composing, specific reading during writing behaviours, and the quality of the texts they produced. For slower and moderately paced writers, local reading and reading at the point of inscription may especially facilitate text planning and may have a positive effect on text quality. Faster writers, on the other hand, devoted comparatively little time to local reading and a higher proportion of time to reading at the point of inscription. The relative percentages of different reading during writing behaviours changed over the course of the composing sessions.

Whereas the first paper focuses on the composition of complete texts, the next two papers report studies in which the writing setting is much more controlled and the writing task is limited to the sentence level. The researchers in these studies created experimental settings in which participants were prompted to produce (partial) sentences under strict conditions. For instance, in Nottbush's study, participants were asked to describe a pictorial representation in a single sentence. Differences in grammatical planning, execution, and control during sentence production were observed, both by logging the writing processes and by using eye tracking. The findings indicated that larger subordinate structures (e.g., "the yellow triangle with the green cross") are cognitively more costly than two smaller noun phrases in the coordinate structure (e.g., "the blue rectangle and the black arrow") in terms of need to refresh information in memory. This load is distributed over the whole phrase. Coordinate structures are more likely to lead to peaks in cognitive load, namely while initiating the coordination and the verb. The analysis of the eye movements showed that eye and typing movements mainly deviate at the beginning of the sentences. Subordinate phrases lead to more and longer gazes toward the stimulus. On a higher level, two main reading strategies were observed: (1) looking ahead for the phrase to be produced (refreshing memory); and (2) looking back for reassuring the text produced so far.

The potential conflict that these two strategies might cause, especially when an error occurs in the text produced so far, is the main focus in the third paper of this special issue. Van Waes, Leijten, and Quinlan designed an experimental setting in which they tried to isolate the interaction with the text produced so far in sentence production. Important questions in their study are: Can writers ignore (low-level) errors in the text produced so far in order to focus on formulating new content? And, do content complexity and error complexity influence the writers' preference to prioritize sentence completion over error correction? In order to investigate this, the researchers devised an experimental paradigm that presented writers with a 
dilemma - an incorrect sentence stem coupled with the demand to formulate a sentence continuation. Also, in this study, data were collected by means of keystroke logging and eye tracking observation. The results revealed that for about $90 \%$ of total items, participants completed the sentence first, and then corrected the error, although in most of the cases the error was fixated before they decided to complete the sentence. Moreover, the study showed that the interplay between two factors, cognitive load and error complexity, appears to influence how writers coordinate error detecting with sentence composing. Also, the accuracy of including three context words is negatively affected by a more intense interaction with the TPSF before completing the sentence.

The latter conclusion could imply that less skilled typists might be at a disadvantage, even if they only correct their errors afterwards. This element in the discussion is one of the topics dealt with in the next article by Johansson, Wengelin, Johansson, and Holmqvist. In their paper, the Lund Research team studied the influence of typing skills and related visual feedback on text production in a more natural context. In an open writing task, they explored text production differences between writers who looked mainly at the keyboard and writers who looked mainly at the monitor while they were typing. As in the previous papers, eye-tracking technology was combined with keystroke logging. The combination of data from these two technologies enabled the researchers to carefully analyze the complex interplay between text production and the reading of the writer's own emerging text. To filter out reading from monitor gazing in general, they used a reading filter that detects reading activity (Markov model for fixation-saccade sequences). The analyses showed that although keyboard gazers read their own text to a less degree than monitor gazers and revise their texts in a much more serial mode, no differences related to the characteristics of the final text were found between the two groups.

The last paper describes aspects of reading behaviour during writing in a slightly different writing condition. In their study, Alamargot, Plane, Lambert, and Chesnet present five case studies of writers performing a writing task in handwriting. The main purpose of their contribution is to enhance our understanding of developmental aspects of writing, and more specifically, the changing relationship between low- and high-level writing processes. Eye movements were recorded and transmitted in real time to a second computer running the Eye and Pen software. Afterwards, the researchers correlated the eye and pen movements with the content characteristics of the scripts produced by the five writers. Results showed a gradual acceleration in low- and high-level processing (pauses and writing fluency), associated with changes in the way the previous text was (re)read. Furthermore, the gradual acquisition of composition skills appeared to allow more experienced writers to undertake more overall planning.

Acknowledgments The guest editors would like to thank Professor R. M. Joshi, the editor-in-Chief of the Reading and Writing journal, for his helpful and cooperative attitude towards this special issue. We also want to thank all the authors as well as reviewers for their contributions. We enjoyed the open and friendly collaboration. This special issue is situated in the context of the COST Action ERN I Learning to Write Effectively (COST IS0703). 


\section{References}

Alamargot, D., Chanquoy, L., \& Rijlaarsdam, G. (Eds.). (2001). Through the models of writing: Studies in writing (Vol. 9). Dordrecht: Kluwer.

Alamargot, D., Chesnet, D., Dansac, C., \& Ros, C. (2006). Eye and pen: A new device to study reading during writing. Behavior Research Methods, Instruments, \& Computers, 38, 287-299.

Alamargot, D., Plane, S., Lambert, E., \& Chesnet, D. (2009). Using eye and pen movements to trace the development of writing expertise: Case studies of a seventh, ninth and twelfth grader, a graduate student, and a professional writer. Reading and Writing: An Interdisciplinary Journal (this issue).

Alvès, R. A., Castro, S. L., de Sousa, L., \& Strömqvist, S. (2007). Influence of typing skill on pauseexecution cycles in written composition. In M. Torrance, L. Van Waes, \& D. Galbraith (Eds.), Writing and cognition: Research and applications. Studies in writing (Vol. 20, pp. 55-65). Dordrecht: Kluwer.

Andersson, B., Dahl, J., Holmqvist, K., Holsanova, J., Johansson, V., \& Karlsson, H. (2006). Combining keystroke logging with eye-tracking. In L. Van Waes, M. Leijten, C. Neuwirth, et al. (Eds.), Writing and digital media: Studies in writing (Vol. 17, pp. 166-172). Oxford: Elsevier.

Berninger, V., Cartwright, A., Yates, C., Swanson, H., \& Abbott, B. (1994). Developmental skills related to writing and reading acquisition in the intermediate grades. Reading and Writing: An Interdisciplinary Journal, 6, 161-196. doi:10.1007/BF01026911.

Bisaillon, J. (2007). Professional editing strategies used by six editors. Written Communication, 24(4), 295-322. doi: $10.1177 / 0741088307305977$.

Breetvelt, I., Van den Bergh, H., \& Rijlaarsdam, G. (1996). Rereading and generating and their relation to text quality: An application of multilevel analysis on writing process data. In G. Rijlaarsdam, H. Van, F. den Bergh, \& M. Couzijn (Eds.), Theories, models, and methodology in writing research: Studies in writing (Vol. 1, pp. 10-20). Amsterdam: Amsterdam University Press.

Butsch, R. (1932). Eye movements and the eye-hand-span in typewriting. Journal of Educational Psychology, 23, 104-121. doi:10.1037/h0073463.

Chesnet, D., \& Alamargot, D. (2006). Eye and pen (Version 1.0) [Computer software]. Poitiers: Octares.

Crain-Thoreson, C., Lippman, M. Z., \& McClendon-Magnuson, D. (1997). Windows on comprehension: Reading processes as revealed by two think-aloud procedures. Journal of Educational Psychology, 89, 579-591. doi:10.1037/0022-0663.89.4.579.

Hacker, D. J., Plumb, C. S., Butterfield, E. C., Quathamer, D., \& Heineken, E. (1994). Text revision: Detection and correction of errors. Journal of Educational Psychology, 86(1), 65-78. doi: 10.1037/0022-0663.86.1.65.

Hayes, J. R. (1996). A new framework for understanding cognition and affect in writing. In C. M. Levy \& S. E. Ransdell (Eds.), The science of writing: Theories, methods, individual differences, and applications (pp. 1-27). Mahwah, New Jersey: Lawrence Erlbaum Associates.

Hayes, J. R., \& Flower, L. S. (1980). Identifying the organization of writing processes. In L. W. Gregg \& E. R. Steinberg (Eds.), Cognitive processes in writing (pp. 3-30). Mahwah, New Jersey: Lawrence Erlbaum Associates.

Holmqvist, K., Holsanova, J., Johansson, V., \& Strömqvist, S. (2004). Perceiving and producing the frog story. In D. Ravid \& H. B.-Z. Shyldkrot (Eds.), Perspectives on language and language development: Essays in honor of Ruth A. Berman (pp. 293-306). Dordrecht: Kluwer.

Inhoff, A., \& Gordon, A. (1998). Eye movements and eye-hand coordination during typing. Psychological Science, 6(6), 153-157.

Johansson, R., Johansson, V., Wengelin, A., \& Holmqvist, K. (2008). Reading during writing, four groups of writers. Lund University Department of Linguistics and Phonetics Working Papers 53, pp 43-59.

Just, P. A., \& Carpenter, A. (1980). A theory of reading: From eye fixations to comprehension. Psychological Review, 87, 329-354. doi:10.1037/0033-295X.87.4.329.

Just, P. A., \& Carpenter, A. (2002). A capacity theory of comprehension: Individual differences in working memory. In T. A. Polk \& C. M. Seifert (Eds.), Cognitive modeling (pp. 131-180). Cambridge, MA: MIT Press.

Kellogg, R. T. (1996). A model of working memory in writing. In C. M. Levy \& S. E. Ransdell (Eds.), The science of writing: Theories, methods, individual differences and applications (pp. 57-71). Hillsdale, NJ: Lawrence Erlbaum. 
Kellogg, R. T. (2008). Training writing skills: A cognitive developmental perspective. Journal of writing research, 1(1), 1-26.

Kintsch, W., \& Rawson, K. A. (2005). Comprehension. In M. Snowling \& C. Hulme (Eds.), The science of reading: A handbook (pp. 209-226). Oxford, UK: Blackwell Publishing.

Leijten, M. (2007). Writing and speech recognition: Observing error correction strategies of professional writers. Utrecht: LOT.

Levelt, W. J. M. (1989). Speaking: From intention to articulation. Cambridge Masschusetts: MIT Press.

Levy, B. A. (1983). Proofreading familiar text-constraints on visual processing. Memory \& Cognition, $11,1-12$.

Liversedge, S. P., \& Findlay, J. M. (2000). Saccadic eye movements and cognition. Trends in Cognitive Sciences, 4, 6-14. doi:10.1016/S1364-6613(99)01418-7.

Longcamp, M., Boucard, C., Gilhodes, J. C., Nazarian, B., Anton, J. L., Roth, M., et al. (2008). Learning through hand- or type-writing influences visual recognition of new graphic shapes: Behavioral and functional imaging evidences. Journal of Cognitive Neuroscience, 20, 802-815. doi:10.1162/ jocn.2008.20504.

McCutchen, D., \& Crain-Thoreson, C. (1994). Phonemic processes in children's reading comprehension. Journal of Experimental Child Psychology, 58, 69-87. doi:10.1006/jecp.1994.1026.

Pianko, S. (1979). The description of the composing processes of college freshmen writers. Research in the Teaching of English, 13, 5-22.

Pilotti, M., Chodorow, M., \& Maxwell, K. (2006). Does the effect of familiarity change with encoding task and time? The Journal of General Psychology, 133, 287-299. doi:10.3200/GENP.133.3. 287-299.

Rayner, K. (1998). Eye movements in reading and information processing: 20 Years of research. Psychological Bulletin, 124, 372-422. doi:10.1037/0033-2909.124.3.372.

Simpson, S., \& Torrance, M. (2007). EyeWrite (Version 5.1) [Computer Software]. SR Research, Osgoode ON, Canada and Nottingham Trent University, Nottingham, UK.

Starr, M. S., \& Rayner, K. (2001). Eye movements during reading: Some current controversies. Trends in Cognitive Sciences, 5, 156-163. doi:10.1016/S1364-6613(00)01619-3.

Wengelin, Å., Torrance, M., Holmqvist, K., Simpson, S., Galbraith, D., Johansson, V., et al. (2009). Combined eye-tracking and keystroke-logging methods for studying cognitive processes in text production. Behavior Research Methods, 41(2), 337-351. doi:10.3758/BRM.41.2.337 